PHYSICAL REVIEW B 90, 144412 (2014)

\title{
Effect of dopants on thermal stability and self-diffusion in iron-nitride thin films
}

\author{
Akhil Tayal, Mukul Gupta, ${ }^{*}$ and N. P. Lalla \\ UGC-DAE Consortium for Scientific Research, University Campus, Khandwa Road, Indore 452 001, India
}

Ajay Gupta

Amity Center for Spintronic Materials, Amity University, Sector 125, NOIDA 201 303, India

M. Horisberger

Laboratory for Developments and Methods, Paul Scherrer Institut, CH-5232 Villigen PSI, Switzerland

Jochen Stahn

Laboratory for Neutron Scattering and Imaging, Paul Scherrer Institut, CH-5232 Villigen PSI, Switzerland

Kai Schlage and H.-C. Wille

Deutsches Elektronen-Synchrotron DESY, Notkestrasse 85, D-22607 Hamburg, Germany

(Received 16 June 2014; revised manuscript received 25 September 2014; published 10 October 2014)

\begin{abstract}
We studied the effect of dopants $(\mathrm{Al}, \mathrm{Ti}, \mathrm{Zr})$ on the thermal stability of iron-nitride thin films prepared using a dc magnetron sputtering technique. Structure and magnetic characterization of deposited samples reveal that the thermal stability together with soft magnetic properties of iron-nitride thin films get significantly improved with doping. To understand the observed results, detailed Fe and $\mathrm{N}$ self-diffusion measurements were performed. It was observed that $\mathrm{N}$ self-diffusion gets suppressed with $\mathrm{Al}$ doping, whereas $\mathrm{Ti}$ or $\mathrm{Zr}$ doping results in somewhat faster $\mathrm{N}$ diffusion. On the other hand, Fe self-diffusion seems to get suppressed with any dopant of which the heat of nitride formation is significantly smaller than that of iron nitride. Importantly, it was observed that $\mathrm{N}$ self-diffusion plays only a trivial role, as compared to Fe self-diffusion, in affecting the thermal stability of iron-nitride thin films. Based on the obtained results, the effect of dopants on the self-diffusion process is discussed.
\end{abstract}

DOI: 10.1103/PhysRevB.90.144412

PACS number(s): 66.30.Fq, 68.60.Dv, 68.65.Ac, 75.50.Bb

\section{INTRODUCTION}

Nitrides of magnetic $3 d$ transition metals are an important class of materials [1]. In particular, iron nitrides $(\mathrm{Fe}-\mathrm{N})$ have been extensively studied owing to the highest magnetic polarization of $\mathrm{Fe}$ as compared to other magnetic elements [2-8]. When added in a relatively small amount $(\leqslant 11$ at. \% $\mathrm{N}), \mathrm{N}$ atoms get dissolved interstitially into the host metal lattice $[9,10]$. Due to dominant Fe-Fe interactions, $\mathrm{N}$ atoms are weakly bonded to $\mathrm{Fe}$ atoms and preserve the structure and the magnetic properties of Fe [11]. Magnetic properties of interstitial Fe-N supersedes pure Fe, giving rise to interesting effects such as giant magnetic moment [12-14], soft magnetic properties [15,16], perpendicular magnetic anisotropy $[14,17,18]$, etc. However, interstitial Fe-N with such a large amount of $\mathrm{N}$ are thermodynamically unfavorable [11], and unlike iron oxides, their enthalpy of formation $\left(\Delta H_{f}^{\circ}\right)$ is at least an order of magnitude more, and even positive as in the case of $\alpha^{\prime \prime}-\mathrm{Fe}_{16} \mathrm{~N}_{2}\left(\Delta H_{f}^{\circ}=85 \pm 47\right)$ [11]. In equilibrium, the solubility limit of interstitial $\mathrm{N}$ in bcc-Fe is just 0.4 at. \% [1]. By using processes such as physical vapor deposition or ion implantation, bcc-Fe lattice is strained to accommodate a much higher amount of interstitial $\mathrm{N}$ (up to 11 at. \%) [19,20]. This intrinsically makes interstitial Fe-N a weakly stable system.

In attempts to make interstitial Fe-N more stable, addition or doping of impurity element(s) was proposed in such a way

\footnotetext{
*mgupta@csr.res.in/dr.mukul.gupta@gmail.com
}

that the amount of impurity must be low enough to affect the structural or the magnetic properties adversely [9,21-34]. Such impurity doped systems were termed as $\mathrm{Fe}-\mathrm{X}-\mathrm{N}$ with $\mathrm{X}=$ few at. $\%$ of $\mathrm{Al}, \mathrm{Ti}, \mathrm{Zr}$, Ta, etc. Although the criteria for choosing such impurity seems to be arbitrary. Variables such as affinity of $\mathrm{X}$ with $\mathrm{N}(f), \Delta H_{f}^{\circ}$ for $\mathrm{X}-\mathrm{N}$, and atomic size of dopants should have been decisive but a systematic study correlating these is still lacking. Table I compares values of $f$, $\Delta H_{f}^{\circ}$, and atomic size for the most popular dopants used in the Fe-N system [11,35-37]. It was suggested in some studies that high $f$ and small $\Delta H_{f}^{\circ}$ of $\mathrm{X}$ may result in higher activation energy for diffusing $\mathrm{N}$ atoms, resulting in a thermally stable phase $[28,35]$. However, $\mathrm{N}$ self-diffusion measurements have not been performed.

In an extensive work by Hultman et al., $\mathrm{N}$ self-diffusion measurements have been carried out in transition metals such as $\mathrm{Cr}, \mathrm{Ti}, \mathrm{Nb}, \mathrm{Zr}, \mathrm{V}$, etc. These transition metals generally have high $f$ and low $\Delta H_{f}^{\circ}$ as compared to $3 d$ magnetic metals [38]. In the absence of a suitable radioactive tracer for $\mathrm{N}$, secondary ion mass spectroscopy (SIMS) of ${ }^{15} \mathrm{~N}$ or a nuclear reaction analysis (NRA) are the only methods to measure $\mathrm{N}$ self-diffusion. Since the depth resolution of these techniques is about $5 \mathrm{~nm}$, N self-diffusion measurements at shorter length scales were not possible. Some attempts have been made to measure $\mathrm{N}$ diffusion in iron mononitride [39] using X-ray photoelectron spectroscopy (XPS) but self-diffusion cannot be measured with XPS.

Neutron reflectivity (NR) technique has emerged as an alternative to do precise diffusion measurements (depth resolution $\sim 0.1 \mathrm{~nm}$ ). Since scattering length density (SLD) of neutrons is 
TABLE I. Atomic radius $(r)$, heat of formation $\left(\Delta H_{f}^{\circ}\right)$, and affinity $(f)$ of $\mathrm{X}-\mathrm{N}$ with respect to $\mathrm{Fe}-\mathrm{N}$.

\begin{tabular}{lccc}
\hline \hline Element & $r(\mathrm{pm})$ & $\Delta H_{f}^{\circ}\left(\mathrm{kJ} \mathrm{mol}^{-1}\right)$ & $f$ \\
\hline $\mathrm{Zr}$ & 206 & -360 & -0.63 \\
$\mathrm{Ti}$ & 176 & -338 & -0.53 \\
$\mathrm{Ta}$ & 200 & -237 & -0.032 \\
$\mathrm{Al}$ & 118 & -321 & -0.028 \\
$\mathrm{Fe}$ & 146 & -10 & - \\
\hline \hline
\end{tabular}

different for isotopes, self-diffusion measurement are feasible with NR. During the last decade, NR has been used to measure self-diffusion in a variety of systems such as Fe self-diffusion in Fe-Zr, [40,41], Fe-Pt [42], etc., Li self-diffusion in $\mathrm{LiNbO}_{3}$ single crystals [43], B self-diffusion in amorphous boron [44], and $\mathrm{N}$ self-diffusion in $\mathrm{Si}_{3} \mathrm{~N}_{4}$ [45], $\mathrm{Si}-\mathrm{C}-\mathrm{N}$ [46], and iron monontrides (Nat. \% 50) [47] compounds. Here it is worth noting that even with $\mathrm{NR}$, measurement of $\mathrm{N}$ self-diffusion in interstitial Fe-N ( $\mathrm{N}$ at. \% 10) [48] is not as easy as in $\mathrm{N}$ rich compounds such as iron monontride ( $\mathrm{N}$ at. $\% \sim 50)$ or in $\mathrm{Si}_{3} \mathrm{~N}_{4}$ due to the much smaller amount of $\mathrm{N}$ and a relatively poor contrast for neutrons between ${ }^{\text {nat }} \mathrm{N}(\mathrm{SLD} 9.36 \mathrm{fm})$ and ${ }^{15} \mathrm{~N}$ (SLD $6.3 \mathrm{fm}$ ). By adopting a special approach with thicker and more number of bilayers, $\mathrm{N}$ self-diffusion could be measured.

In the present work we have addressed the above-mentioned issues in the following way: (i) We used $\mathrm{Al}$ and $\mathrm{Zr}$ dopants which have atomic sizes on extreme ends (see Table I) but similar $\Delta H_{f}^{\circ}$, (ii) we measured $\mathrm{N}$ self-diffusion using $\mathrm{NR}$ (and SIMS) in undoped and $\mathrm{Al}, \mathrm{Ti}$, and $\mathrm{Zr}$ doped interstitial Fe-N, and (iii) besides, we measured Fe self-diffusion using NR and nuclear resonance reflectivity. The doping level of $\mathrm{X}=\mathrm{Al}$, $\mathrm{Ti}$, or $\mathrm{Zr}$, was varied according to their atomic size, affinity, and $\Delta H_{f}^{\circ}$ of X-N. From Table I it can be seen that these parameters decrease in an order such that they are maximum for $\mathrm{Zr}$ followed by $\mathrm{Ti}$ and $\mathrm{Al}$. Therefore, it is expected that small doping of $\mathrm{Zr}$ relative to $\mathrm{Al}$ would have a similar effect on thermal stability. Hence, we have chosen the atomic concentration of $\mathrm{Al}, \mathrm{Ti}$, and $\mathrm{Zr}$ as 5.6, 4.1, and 3.2 at. \%, respectively. By doing systematic structural and magnetic characterization, we found that the thermal stability increases significantly both with $\mathrm{Al}$ and $\mathrm{Zr}$ doping. Additionally, magnetization measurements revealed formation of a stable soft-magnetic phase with dopants. To investigate the mechanism leading to enhancement in thermal stability, Fe and $\mathrm{N}$ self-diffusion measurements were carried out. It was found that $\mathrm{N}$ self-diffusion suppresses (to some extent) only with $\mathrm{Al}$ doping, other dopants ( $\mathrm{Ti}$ or $\mathrm{Zr}$ ) results in even faster diffusion. On the other hand, dopants have a much more significant effect in suppressing Fe self-diffusion. It was found that $\mathrm{N}$ diffusion takes place through an interstitial exchange mechanism, and during this process both structure and magnetic properties remain unaffected. This result is in contradiction with the assumption that $\mathrm{N}$ diffusion leads to thermal instability in the Fe-N system. We found that structural instabilities are more correlated with $\mathrm{Fe}$ self-diffusion rather than $\mathrm{N}$ selfdiffusion. Based on obtained results, the effect of dopants on thermal stability and self-diffusion is discussed in this work.

\section{EXPERIMENT}

$\mathrm{Fe}-\mathrm{X}-\mathrm{N}$ thin film samples with $\mathrm{X}=\mathrm{Al}$, Ti, or $\mathrm{Zr}$ were deposited using a dc-magnetron sputtering technique simultaneously on $\mathrm{Si}(100)$ and float glass substrates at room temperature. Pure $\mathrm{Fe},[\mathrm{Fe}+\mathrm{Al}],[\mathrm{Fe}+\mathrm{Ti}]$, and $[\mathrm{Fe}+\mathrm{Zr}]$ composite targets were sputtered using a mixture of $\mathrm{N}_{2}(1.5 \mathrm{sccm})$ and $\mathrm{Ar}$ $(8.5 \mathrm{sccm})$ gases. To get the desired composition of $\mathrm{Al}, \mathrm{Ti}$, and $\mathrm{Zr}$, relative coverage of $\mathrm{Al}, \mathrm{Ti}$, or $\mathrm{Zr}$ on $\mathrm{Fe}$ target was varied taking into account their relative sputter yields. Composition of deposited samples was measured using energy dispersive $\mathrm{x}$-ray analysis and secondary neutral mass spectroscopy. It comes out to be $5.6( \pm 1.2)$ at. $\%$ for $\mathrm{Al}, 4.1( \pm 1.4)$ at. $\%$ for $\mathrm{Ti}$, and $3.2( \pm 1.3)$ at. $\%$ for $\mathrm{Zr}$. The composition of nitrogen was measured with SIMS using a reference sample of known composition and comes out to be $\sim 11$ at. $\%( \pm 1)$ in all the samples. This was also confirmed using conversion electron Mössbauer spectroscopy in the undoped sample. A base pressure of about $1 \times 10^{-7}$ mbar was achieved prior to the deposition. During the deposition, partial pressure in the chamber was about $4 \times 10^{-3}$ mbar. More details about the deposition system are given elsewhere [10,47].

Multilayer samples with nominal structure: substrate $\mid\left[{ }^{\text {nat }} \mathrm{Fe}-\mathrm{X}-\left.\mathrm{N}(6 \mathrm{~nm})\right|^{57} \mathrm{Fe}-\mathrm{X}-\mathrm{N}(6 \mathrm{~nm})\right]_{\times 10}$ and substrate $\mid\left[\mathrm{Fe}-\mathrm{X}-{ }^{\mathrm{nat}} \mathrm{N}(9 \mathrm{~nm}) \mid \mathrm{Fe}-\mathrm{X}-{ }^{15} \mathrm{~N}(9 \mathrm{~nm})\right]_{\times 25}$ were prepared for $\mathrm{Fe}$ and $\mathrm{N}$ self-diffusion measurements using neutron reflectivity, with $\mathrm{X}=0, \mathrm{Al}, \mathrm{Ti}$, and $\mathrm{Zr}$. Here "nat" indicates isotopes of $\mathrm{Fe}$ and $\mathrm{N}$ obtained in natural abundance. Isotope enrichment of ${ }^{57} \mathrm{Fe}$ layers exceeds to about $95 \%$, and that of ${ }^{15} \mathrm{~N}$ is about $98 \%$. For $\mathrm{N}$ diffusion measurements with SIMS a special trilayer structure: substrate|[Fe-X-nat $\mathrm{N}(110$ $\left.\mathrm{nm})\left|\mathrm{Fe}-\mathrm{X}-{ }^{15} \mathrm{~N}(2 \mathrm{~nm})\right| \mathrm{Fe}-\mathrm{X}-{ }^{\text {nat }} \mathrm{N}(110 \mathrm{~nm})\right]$, with $\mathrm{X}=0$, $\mathrm{Al}$, and $\mathrm{Zr}$ was deposited. Such structure is expected to give a peak when looking at ${ }^{15} \mathrm{~N}$ depth profile. For $\mathrm{Fe}$ diffusion measurements with nuclear resonance reflectivity, substrate $\mid\left[{ }^{\text {nat }} \mathrm{Fe}-\mathrm{N}(2.2 \mathrm{~nm}) \mid{ }^{57} \mathrm{Fe}-\mathrm{N}(2.2 \mathrm{~nm})\right]_{\times 10}$ and substrate $\mid\left[{ }^{\text {nat }} \mathrm{Fe}-\mathrm{Al}-\mathrm{N}(2 \quad \mathrm{~nm}) \mid{ }^{57} \mathrm{Fe}-\mathrm{Al}-\mathrm{N}(2 \quad \mathrm{~nm})\right]_{\times 10}$ samples were deposited. All samples were deposited using identical deposition conditions. Structural and magnetic characterization shown in this work was carried out on chemically homogeneous isotopic multilayer $\left(\mathrm{Fe} /{ }^{57} \mathrm{Fe}\right)$ samples with total thickness of about $120 \mathrm{~nm}$. Samples with $\mathrm{X}=0, \mathrm{Al}, \mathrm{Zr}$, and Ti are named as Fe-N, Fe-Al-N, Fe-Zr-N, and Fe-Ti-N, respectively throughout this work.

Structural characterization was done using $\mathrm{X}$-ray diffraction (XRD) on a Bruker D8 Advance x-ray diffractometer with $\mathrm{Cu} K \alpha$ x-ray source in $\theta-2 \theta$ geometry. For a detailed study of the microstructure of the samples transmission electron microscopy measurements were carried out using a Tecnai$G^{2}-20$ TEM operating at $200 \mathrm{kV}$. Magnetic properties were studied using a Quantum Design superconducting quantum interference device-vibrating sample magnetometer (S-VSM) and conversion electron Mössbauer spectroscopy (CEMS). Self-diffusion measurements of $\mathrm{Fe}$ was performed using polarized neutron reflectivity (PNR) and nuclear resonance reflectivity (NRR). For N self-diffusion measurements PNR and SIMS techniques were used. The PNR measurements were carried out on AMOR reflectometer at SINQ, PSI Switzerland. A magnetic field of about $400 \mathrm{kA} / \mathrm{m}$ was applied to saturate the samples magnetically. For diffusion 

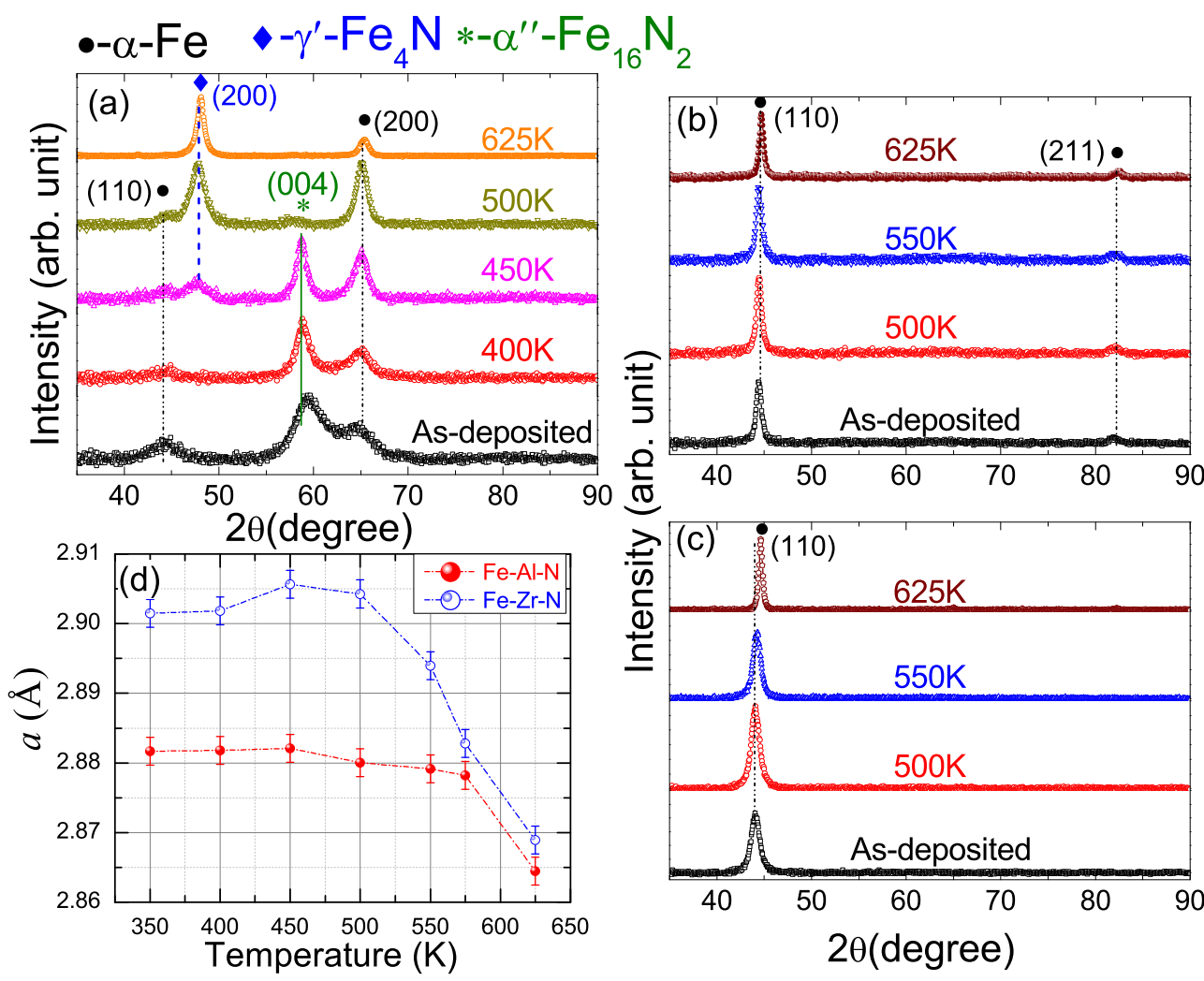

FIG. 1. (Color online) XRD patterns of (a) Fe-N, (b) Fe-Al-N, and (c) Fe-Zr-N samples in the as-deposited state and after annealing at various temperatures. For better comparison scales are vertically translated. (d) Variation of lattice constant with annealing temperature for $\mathrm{Fe}-\mathrm{Al}-\mathrm{N}$ and $\mathrm{Fe}-\mathrm{Zr}-\mathrm{N}$ samples.

measurements only spin-up reflectivity were used. The NRR measurements were performed using $14.4 \mathrm{keV}$ radiation at $\mathrm{P} 01$ beamline, PETRA III, DESY, Germany. SIMS measurements were performed on a Hiden Analytical SIMS Workstation. A base pressure of $8 \times 10^{-10}$ mbar was achieved in the SIMS chamber. A beam of $\mathrm{O}_{2}^{+}$primary ions (energy $5 \mathrm{keV}$ and current $400 \mathrm{nA}$ ) was used to sputter samples. During measurements pressure in the chamber was about $8 \times 10^{-8}$ mbar. To investigate the thermal stability ex situ annealing of samples was performed for about $2 \mathrm{~h}$ in a separate vacuum furnace.

\section{RESULTS}

\section{A. X-ray diffraction}

Figures 1(a)-1(c) show the XRD patterns of Fe-N, Fe-Al-N, and $\mathrm{Fe}-\mathrm{Zr}-\mathrm{N}$ samples in the as-deposited state and after annealing at various temperatures. XRD patterns taken at selected temperatures are shown in the figure. From Fig. 1(a) it can be seen that in the as-deposited state distinct broad peaks corresponding to bcc $\alpha-\mathrm{Fe}(\mathrm{N})$ and $\alpha^{\prime \prime}-\mathrm{Fe}_{16} \mathrm{~N}_{2}$ phase are appearing [14]. It is known that in these phases nitrogen atoms are occupied within the interstitial sites of Fe lattice in random and ordered fashion, respectively [49]. With annealing up to $450 \mathrm{~K}$, peak intensity increases and the width reduces indicating an enhancement in nitrogen ordering. Above this temperature $\alpha^{\prime \prime}$ phase almost disappears. With further annealing, intensity of the peak corresponding to $\gamma^{\prime}-\mathrm{Fe}_{4} \mathrm{~N}$ rises implying growth of the $\gamma^{\prime}$ phase. Contrary to this, the behavior of Fe-Al-N and Fe-Zr-N samples are different. From Figs. 1(b) and $1(\mathrm{c})$ it can be seen that in the as-deposited state, only peaks corresponding to $\alpha-\mathrm{Fe}(\mathrm{N})$ phase are observed. It appears that the doping has diminished $\mathrm{N}$ ordering that was observed in the undoped sample. Annealing of the samples up to $500 \mathrm{~K}$ shows no change in the XRD pattern. Moreover, no extra peaks corresponding to any other phases can be seen even after $625 \mathrm{~K}$. This indicates that the thermal stability of the films gets significantly improved with doping. From (110) reflection, average crystallite size in the samples was calculated using Scherrer formula [50] and found to be 15 and $9 \mathrm{~nm}$ for Fe-Al-N and Fe-Zr-N samples, respectively. Moreover, lattice constant (a) of doped samples in the as-deposited state is compared with undoped samples. It was observed that with Al doping the average unit cell volume of $\mathrm{Fe}$ gets reduced by about $0.5 \%$, whereas, in case of $\mathrm{Zr}$, it expands by about $2 \%$. These results can be attributed to the varied atomic size of $\mathrm{Al}$ and $\mathrm{Zr}$ with respect to Fe. For doped samples it can be seen that the peak position corresponding to the (110) reflection shifts to higher $2 \theta$ above $500 \mathrm{~K}$. Figure 1(d) shows variation of the lattice constant with annealing temperature for Fe-Al-N and Fe-Zr-N samples. Up to $575 \mathrm{~K}$ a remains almost constant with $\mathrm{Al}$ doping, while it shows a marginal increase above $400 \mathrm{~K}$ and a steep decrease above $575 \mathrm{~K}$. Whereas with $\mathrm{Zr}$ doping a steep decrease in $a$ starts already at $500 \mathrm{~K}$. It signifies that $\mathrm{Al}$ doping results in relatively superior structural stability. 

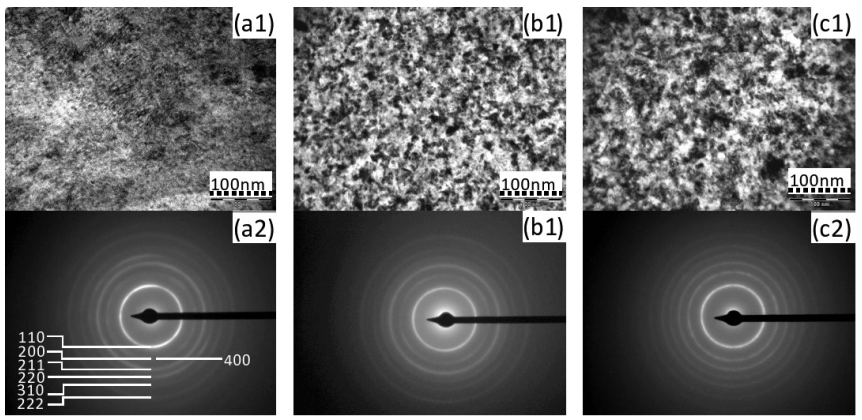

FIG. 2. TEM micrographs and corresponding electron diffraction rings of as-deposited Fe-N [(a1), (a2)], Fe-Al-N [(b1), (b2)], and Fe-Zr-N [(c1), (c2)] thin films.

\section{B. Transmission electron microscopy}

To get more insight about the microstructure of the samples, TEM measurements were carried out in as-deposited samples. Figure 2 shows TEM micrographs and corresponding electron diffraction (ED) rings of Fe-N [(a1), (a2)], Fe-Al-N [(b1), (b2)], and Fe-Zr-N [(c1), (c2)] samples. It can be seen that the microstructure of the undoped sample is different from doped samples. Upon doping granular microstructure appears with an average grain size of about $15 \mathrm{~nm}$ in Al doped samples and about $10 \mathrm{~nm}$ in $\mathrm{Zr}$ doped samples. In an undoped sample, grain size is typically about $6 \mathrm{~nm}$. These values of grain size correlate very well with those obtained from XRD measurements. The ED rings of undoped as well as doped samples were indexed corresponding to bcc $\alpha-\mathrm{Fe}(\mathrm{N})$. It may be noted that the (200) reflection corresponding to $\alpha-\mathrm{Fe}(\mathrm{N})$ phase, overlaps with the (004) reflection of $\alpha^{\prime \prime}-\mathrm{Fe}_{16} \mathrm{~N}_{2}$ [13]. A closer look at the intensity distribution of diffraction rings reveals that it is slightly more inhomogeneous in an undoped sample. This could be due to texturing in the growth. Therefore, our TEM measurements show that the microstructure of undoped and doped samples is similar and the differences obtained are only of grain size and texturing. Besides, diffraction rings corresponding to any other iron nitride can neither be seen in undoped nor in $\mathrm{Al}$ or $\mathrm{Zr}$ doped samples.

\section{Magnetic measurements}

We performed PNR measurements on as-deposited samples. It is known that for magnetic thin films, PNR is a unique technique to measure the magnetic moment very precisely irrespective of sample dimension. The difference between the critical edges of spin-up (Fig. 3) and spin-down (not shown) reflectivities provide information about the magnetic moment, as samples were magnetically saturated [51]. Here the observed Bragg peak is due to bilayer periodicity of ${ }^{57} \mathrm{Fe} /{ }^{\text {nat }} \mathrm{Fe}$ having different neutron scattering length contrast. To obtain information about the bilayer thickness and magnetic moment, PNR data were fitted using SimulReflc software [52]. For Fe-N, Fe-Al-N, and Fe-Zr-N samples obtained bilayer thickness are $13,13.1$, and $12.3 \mathrm{~nm}$, and value of the magnetic moment is $1.8,1.7$, and $1.65 \mu_{B}$, respectively. These values of

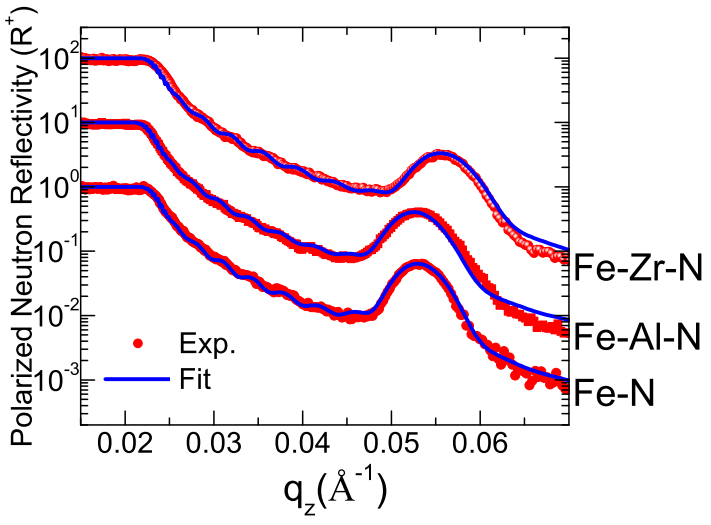

FIG. 3. (Color online) Spin-up reflectivity patterns of asdeposited Sub. $\mid\left[\mathrm{Fe}-\mathrm{N}(6.53 \mathrm{~nm}){ }^{57} \mathrm{Fe}-\mathrm{N}(6.53 \mathrm{~nm})\right]_{\times 10}$, Sub. $\mid[\mathrm{Fe}-$ Al-N(6.55 nm) $\left.{ }^{57} \mathrm{Fe}-\mathrm{Al}-\mathrm{N}(6.55 \mathrm{~nm})\right]_{\times 10}$, and Sub.|[Fe-Zr-N(6.15 $\left.\mathrm{nm})\left.\right|^{57} \mathrm{Fe}-\mathrm{Zr}-\mathrm{N}(6.15 \mathrm{~nm})\right]_{\times 10}$ thin films. Patterns are vertically translated for clarity.

magnetic moment are in agreement with those reported for the $\mathrm{Fe}-\mathrm{N}$ system having a similar amount of nitrogen [10,53,54].

To investigate the implication of doping on magnetic properties, we also did M-H (magnetization-applied magnetic field) measurements. Figures 4(a)-4(c) show normalized M-H loops of the as-deposited samples. The inset in figures shows a blown up region near the coercive field. A typical "transcritical shape" of the M-H loop [Fig. 4(a)] for the undoped sample suggests that the film exhibits perpendicular magnetic anisotropy (PMA). Recently, Ji et al. have reported similar type M-H loops for epitaxial $\alpha^{\prime \prime}-\mathrm{Fe}_{16} \mathrm{~N}_{2}$ thin films [14]. Here it was claimed that observed magnetic anisotropy originates due to magnetocrystalline anisotropy in the system, which originates due to tetragonal distortion of bcc Fe lattice as $\mathrm{N}$ atoms occupy interstitial positions. Magnetocrystalline anisotropy constant $\left(K_{u}\right)$ can be calculated using $K_{u}=H_{k} \times M_{s} / 2$ [14]; where $M_{s}$ is saturation magnetization and $H_{k}$ is an anisotropy field which has a value close to $H_{s}$ saturation field as indicated in Fig. 4(a). We obtain $K_{u} \sim 10^{5} \mathrm{~J} \mathrm{~m}^{-3}$, which is close to the reported value [14]. Additionally, obtained values of coercivity $\left(H_{C}\right)$ is $10 \mathrm{kA} / \mathrm{m}$. Apart from this, the ratio of remanence magnetization and $M_{S}$ was found to be 0.4 , indicating PMA. For the Fe-Al-N and Fe-Zr-N samples, M-H loops are square shaped with a very small value of $H_{C}(\sim 1 \mathrm{~A} / \mathrm{m})$, indicating formation of a soft magnetic phase. Furthermore, an open
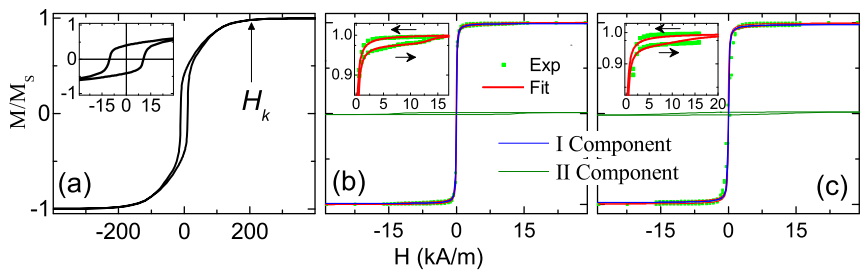

FIG. 4. (Color online) M-H loops of as-deposited (a) Fe-N, (b) $\mathrm{Fe}-\mathrm{Al}-\mathrm{N}$, and (c) Fe-Zr-N thin films. Inset of figure shows a blown up region near the coercive field. Arrows in (b) and (c) show direction of applied magnetic field during $\mathrm{M}-\mathrm{H}$ measurements. For $\mathrm{Al}$ and $\mathrm{Zr}$ doped samples $\mathrm{M}-\mathrm{H}$ loops were fitted by two components using Eq. (1). 


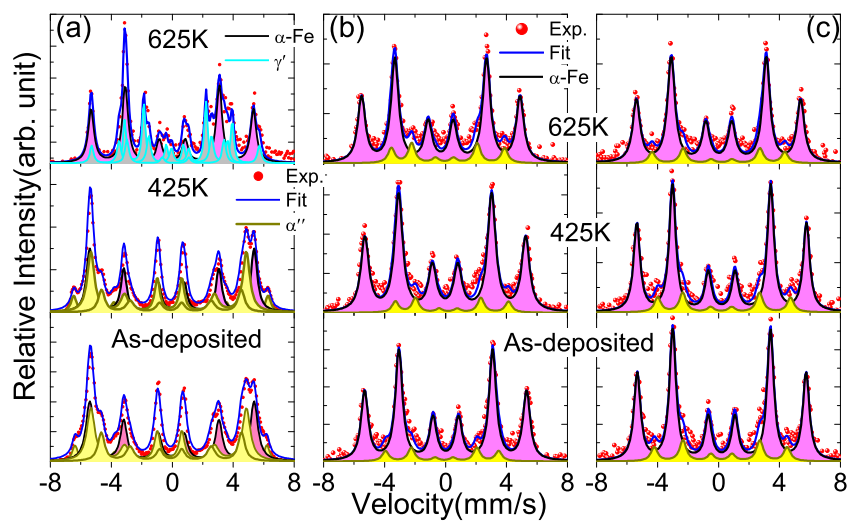

FIG. 5. (Color online) CEMS spectra of (a) Fe-N, (b) Fe-Al-N, and (c) Fe-Zr-N thin films in the as-deposited state and after annealing at various temperatures.

region near the saturation field can be seen [as shown in the inset of Figs. 4(b) and 4(c)] indicating presence of hard magnetic phase. To extract the amount of this phase we have fitted the normalized $\mathrm{M}-\mathrm{H}$ loops assuming a soft and a hard component using the following expression $[55,56]$ :

$$
M(H)=\sum_{i=1}^{n} \frac{2 M_{S}^{i}}{\pi} \arctan \left|\frac{H \pm H_{C}^{i}}{H_{C}^{i}} \tan \left(\frac{\pi S^{i}}{2}\right)\right| .
$$

Here $M_{S}^{i}$ is the saturation magnetization, $H_{C}^{i}$ is the coercivity, and $S^{i}$ is ratio of remanent to saturation magnetization $\left(M_{R} / M_{S}\right)$ of the $i$ th component of a M-H loop. It was observed that the amount of soft magnetic phase is about $98 \%$ and that of hard magnetic phase with $H_{C}=12 \mathrm{kA} / \mathrm{m}$ is about $2 \%$ in both $\mathrm{Al}$ and $\mathrm{Zr}$ doped samples.

\section{Conversion electron Mössbauer spectroscopy}

Mössbauer spectroscopy is a versatile technique to probe the local structure around a resonant nuclei. From our XRD results, discussed in Sec. III A, it was observed that in the asdeposited state $\mathrm{Fe}-\mathrm{N}$ films have mixed $\alpha^{\prime \prime}-\mathrm{Fe}_{16} \mathrm{~N}_{2}$ and $\alpha$ - $\mathrm{Fe}(\mathrm{N})$ phases. Whereas in $\mathrm{Al}$ or $\mathrm{Zr}$ doped samples, only $\alpha-\mathrm{Fe}(\mathrm{N})$ phase can be seen. Using Mössbauer spectroscopy relative volume fraction of the different Fe-N phases can be obtained. Figures 5(a)-5(c) show selective CEMS spectra of Fe-N (a), Fe-Al-N (b), and Fe-Zr-N (c) thin films in the as-deposited state and after annealing at 425 and $625 \mathrm{~K}$. We fitted the observed CEMS spectra using NORMOS SITE and DIST programs [57].

CEMS spectrum of the as-deposited Fe-N sample can only be fitted assuming four sextet. Three of them corresponding to the $\alpha^{\prime \prime}-\mathrm{Fe}_{16} \mathrm{~N}_{2}$ phase (hyperfine field $=39,31.6$, and $28.5 \mathrm{~T}$ ) and the remaining to $\alpha-\mathrm{Fe}$ (hyperfine field $=33 \mathrm{~T}$ ), the obtained fitting parameters correlate well with previously reported values [13]. Additionally, area of the fitted sextets can be used to calculate the relative concentration of these phases, which are tabulated in Table II. As can be seen, after annealing at $425 \mathrm{~K}$ the values are almost similar to the as-deposited sample, but at a higher annealing temperature of $500 \mathrm{~K}$ (not shown) and $625 \mathrm{~K}$, the $\alpha^{\prime \prime}-\mathrm{Fe}_{16} \mathrm{~N}_{2}$ phase disappears and the $\gamma^{\prime}$ phase starts to grow. The relative area under $\gamma^{\prime}$ and $\alpha-\mathrm{Fe}$ phase can be used [17] to calculate nitrogen concentration which comes out to be $(11 \pm 2)$ at. \%, in agreement with our SIMS measurements.

Moreover, it may be noted here that the intensity ratio of the second and third line $\left(R_{23}\right)$ in CEMS spectrum can be used to obtain the spin texture [58]. In the absence of any spin texture, $R_{23}=4$ and $\phi=90 \operatorname{deg}(\phi$ is the angle between incident $\gamma$ ray and average spin orientation in the film). The value of $R_{23}$ and $\phi$ reduces as spin gets aligned perpendicularly. In our case the average value of $R_{23}=1.35$ and that of $\phi \sim 45 \mathrm{deg}$ in the as-deposited sample. With annealing $R_{23}$ becomes close to 4 and $\phi \sim 90 \mathrm{deg}$, indicating disappearance of spin texture. These results are in agreement with PMA obtained from the M-H loop for the as-deposited undoped sample.

In comparison to $\mathrm{Fe}-\mathrm{N}$, CEMS spectra of doped samples are completely different and remain almost similar to the asdeposited samples, even after annealing at $625 \mathrm{~K}$, as expected from XRD results. Besides, it was found that CEMS spectra of $\mathrm{Fe}-\mathrm{Al}-\mathrm{N}$ and $\mathrm{Fe}-\mathrm{Zr}-\mathrm{N}$ samples can only be fitted assuming two components - one corresponding to $\alpha$-Fe phase with hyperfine field about $33 \mathrm{~T}$ and another with a reduced hyperfine field. As our magnetization measurements on doped samples show presence of a hard magnetic phase, the phase formed with a reduced hyperfine field may be attributed to it. The values of a hyperfine field for such a hard phase are $23 \mathrm{~T}$ for Fe-Al-N and $27 \mathrm{~T}$ for $\mathrm{Fe}-\mathrm{Zr}-\mathrm{N}$ samples. The area ratio for this phase comes out to be about $12 \%$. Which could be due to a distribution of a hard phase having different hyperfine fields. Such a hard phase can appear due to some ordering of $\mathrm{N}$ atoms [13]. Since in our ED rings any other $\mathrm{Fe}-\mathrm{N}$ phase cannot be seen, the observed hard phase have originated due to ordering of $\mathrm{N}$ atoms within the $\alpha-\mathrm{Fe}(\mathrm{N})$ phase.

It may be noted that our XRD, TEM, magnetization, and CEMS measurements present comprehensive information about the structural and magnetic properties of samples in the as-deposited state and after annealing at different temperatures. While an undoped sample undergoes phase formation upon annealing, both local and long range stability seem to get significantly improved with $\mathrm{Al}$ and $\mathrm{Zr}$ doping. However, thermal stability seems to be better with Al than with $\mathrm{Zr}$. In order to understand the mechanism leading to thermal stability, we performed self-diffusion measurements of $\mathrm{Fe}$ and $\mathrm{N}$ in our samples, which will be discussed in the next section.

TABLE II. Volume fraction of various Fe-N phases obtained from fitting CEMS spectra. Here "H" stands for a hard magnetic phase.

\begin{tabular}{lrrr}
\hline \hline Temperature & Fe-N & FeAlN & FeZrN \\
\hline As-deposited & $59 \%\left(\alpha^{\prime \prime}-\mathrm{Fe}_{16} \mathrm{~N}_{2}\right)+41 \%(\alpha-\mathrm{Fe})$ & $89 \%(\alpha-\mathrm{Fe})+11 \%(\mathrm{H})$ & $86 \%(\alpha-\mathrm{Fe})+14 \%(\mathrm{H})$ \\
$425 \mathrm{~K}$ & $60 \%\left(\alpha^{\prime \prime}-\mathrm{Fe}_{16} \mathrm{~N}_{2}\right)+40 \%(\alpha-\mathrm{Fe})$ & $90 \%(\alpha-\mathrm{Fe})+10 \%(\mathrm{H})$ & $86 \%(\alpha-\mathrm{Fe})+14 \%(\mathrm{H})$ \\
$625 \mathrm{~K}$ & $48 \%\left(\gamma^{\prime}\right)+52 \%(\alpha-\mathrm{Fe})$ & $88 \%(\alpha-\mathrm{Fe})+12 \%(\mathrm{H})$ & $88 \%(\alpha-\mathrm{Fe})+12 \%(\mathrm{H})$ \\
\hline \hline
\end{tabular}




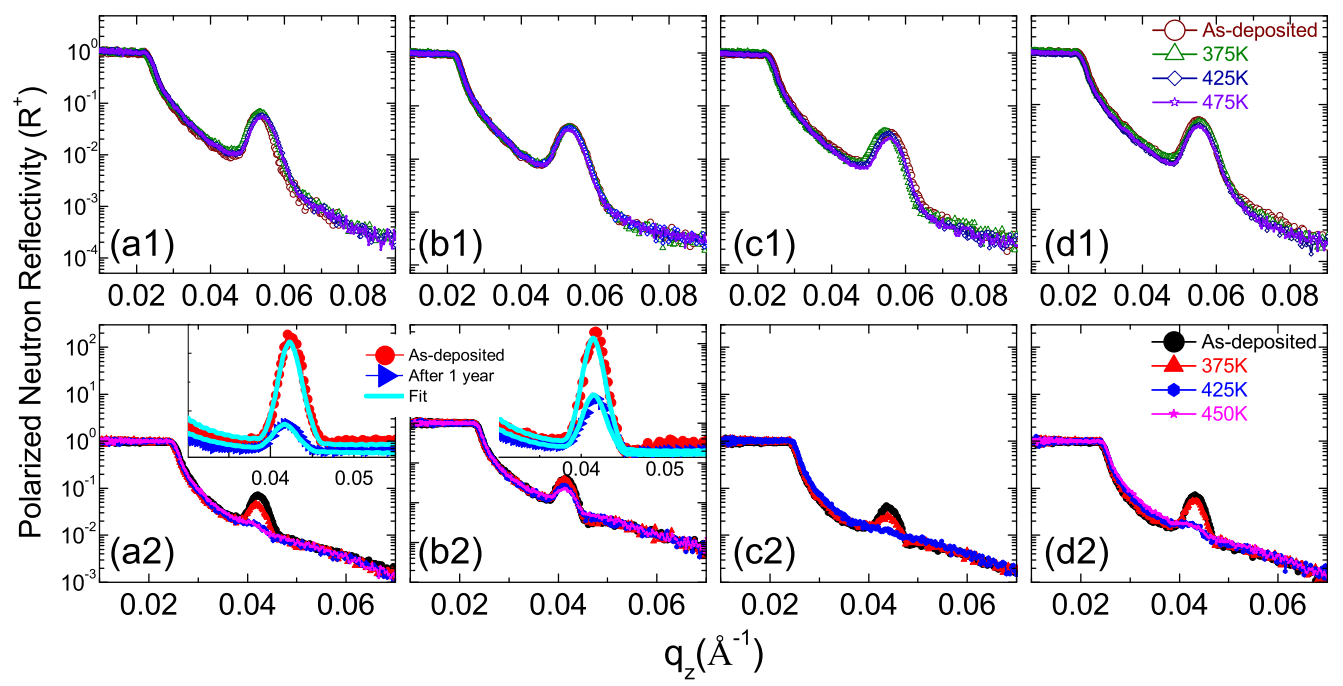

FIG. 6. (Color online) PNR patterns of Sub. $\mid\left[\mathrm{Fe}-\mathrm{X}-\mathrm{N} \mid{ }^{57} \mathrm{Fe}-\mathrm{X}-\mathrm{N}\right]_{\times 10}$ for $\mathrm{X}=0$ (a1), $\mathrm{Al}(\mathrm{b} 1), \mathrm{Zr}(\mathrm{c} 1)$, Ti (d1) and Sub.|[Fe-X-N|Fe-X- $\left.{ }^{15} \mathrm{~N}\right] \times 25$ for $\mathrm{X}=0$ (a2), $\mathrm{Al}$ (b2), $\mathrm{Zr}$ (c2), $\mathrm{Ti}(\mathrm{d} 2)$ in the as-deposited state and after annealing at various temperatures. Inset of (a2) and (b2) compares PNR patterns of Fe-N and Fe-Al-N samples taken just after deposition and measured after one year.

\section{E. Self-diffusion measurements}

In this section we present self-diffusion measurements performed using PNR, SIMS, and NRR. It is known that these techniques are the only methods to probe self-diffusion in stable isotopes. While reflectivity techniques (PNR and NRR) offer an excellent depth resolution of about $0.1 \mathrm{~nm}$ [47,59-61], the information obtained from these techniques is "indirect" as they are based on X-ray/neutron scattering. SIMS, on the other hand, provides depth profile of isotopes giving a "direct" information of diffusivity. Although depth resolution of SIMS is about $5 \mathrm{~nm}$, a comparison of reflectivity and SIMS provides reliable information about self-diffusion. In this work we measured Fe self-diffusion using PNR and NRR and N self-diffusion using PNR and SIMS. Complementarities of different techniques was used to get precise information of $\mathrm{Fe}$ and $\mathrm{N}$ self-diffusion.

Figure 6 shows PNR patterns of Fe-N [(a1), (a2)], Fe-Al-N [(b1), (b2)], Fe-Zr-N [(c1), (c2)], and Fe-Ti-N [(d1), (d2)] samples in the as-deposited state and after annealing at various temperatures. In Figs. 6(a1)-6(d1) and Figs. 6(a2)-6(d2) a Bragg peak originating due to scattering length $\left(b_{n}\right)$ contrast of ${ }^{57} \mathrm{Fe} /{ }^{\text {nat }} \mathrm{Fe}$ and ${ }^{15} \mathrm{~N} /{ }^{\text {nat }} \mathrm{N}$, respectively. X-ray reflectivity measurements (not shown) performed on these samples do not show any Bragg peak due to lack of contrast between isotopes. It confirms that films are chemically homogeneous. Since our samples are iron rich and a large difference between the value of $b_{n}$ for ${ }^{\text {nat }} \mathrm{Fe}(=9.45 \mathrm{fm})$ and ${ }^{57} \mathrm{Fe}(=2.3 \mathrm{fm})$ exists, considerably intense Bragg peak can be seen even with 10 repetitions of bilayers. However, for nitrogen, relatively smaller difference in $b_{n}$ for ${ }^{\text {nat }} \mathrm{N}(=9.36 \mathrm{fm})$ and ${ }^{15} \mathrm{~N}(=6.3 \mathrm{fm})$ and low nitrogen concentration $(\sim 11$ at. $\%)$, makes it very difficult to measure nitrogen diffusion. Probably this is the reason that nitrogen self-diffusion has not yet been reported for magnetic $\mathrm{Fe}-\mathrm{X}-\mathrm{N}$ thin films. In order to get the appreciable intensity of Bragg peak, we increased bilayer thickness and the number of repetitions. From fitting of the PNR data [52] measured bilayer period for undoped and $\mathrm{Al}, \mathrm{Zr}$, or $\mathrm{Ti}$ doped samples are $18.8,18.4,17.6$, and 17.2 nm, respectively. From Figs. 6(a2)-6(d2) it can be seen, a Bragg peak of appreciable intensity due to ${ }^{15} \mathrm{~N} /{ }^{\text {nat }} \mathrm{N}$ contrast can be clearly observed. Although its intensity is considerably low (as compared to ${ }^{57} \mathrm{Fe} /{ }^{\text {nat }} \mathrm{Fe}$ ), as expected.

To study self-diffusion, samples were annealed in a vacuum furnace at different temperatures for $1 \mathrm{~h}$ at each temperature. For ${ }^{57} \mathrm{Fe} /{ }^{\text {nat }} \mathrm{Fe}$ samples, we find that the intensity of the peak does not change with annealing [Figs. 6(a1)-6(d1)] indicating that up to a temperature of $475 \mathrm{~K}$, self-diffusion of iron is negligible. On the other hand, in ${ }^{15} \mathrm{~N} /{ }^{\text {nat }} \mathrm{N}$ samples, noticeable nitrogen diffusion can be seen even at a temperature of $375 \mathrm{~K}$, and at $425 \mathrm{~K}$ nitrogen gets almost completely diffused in all but Al doped samples as shown in Figs. 6(a2)-6(d2). Incidentally, we measured an undoped and an Al doped samples kept at room temperature just after deposition and after a gap of about 1 year (355 days). Inset of Fig. 6 compares PNR patterns of $\mathrm{Fe}-\mathrm{N}$ (a2) and Fe-Al-N (b2) samples taken immediately after deposition and after 355 days kept at room temperature. It can be seen that $\mathrm{N}$ diffusion suppresses with $\mathrm{Al}$ doping even at room temperature. This is a clear indication that nitrogen self-diffusion gets remarkably suppressed with Al doping. In contrast to this, with $\mathrm{Zr}$ doping behavior of nitrogen diffusion is surprisingly unusual, as $\mathrm{Zr}$ doping results in somewhat faster nitrogen diffusion compared to an undoped Fe-N sample.

From the decay in the intensity of Bragg peak selfdiffusivity in the samples can be calculated using the following expression [47,59-61]:

$$
\ln \left[\frac{I(t)}{I(0)}\right]=\frac{-8 \pi^{2} D t}{d^{2}},
$$

where $I(0)$ is the intensity of the first order Bragg peak at time $t=0$ (before annealing), $d$ is the bilayer thickness, and $D$ is diffusivity. Obtained values of $D$ for Fe-N and Fe-Al-N samples kept at room temperature for about 1 year comes out to be $2 \times 10^{-25}$ and $1 \times 10^{-25} \mathrm{~m}^{2} \mathrm{~s}^{-1}$, respectively. Information about diffusivity can also be obtained from fitting of PNR data. 


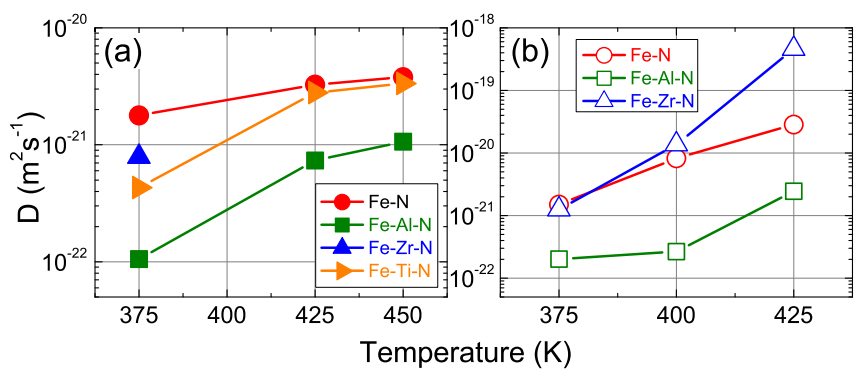

FIG. 7. (Color online) Self-diffusivity of nitrogen obtained from (a) PNR and (b) SIMS measurements, solid lines are guide to eye. Typical error bars in the measurements are about the size of scatters.

Following the fitting procedure as mentioned in Sec. IIIC, obtained values of diffusion length are 3.5 and $2.5 \mathrm{~nm}$ for $\mathrm{Fe}-\mathrm{N}$ and Fe-Al-N samples, respectively, which are in close agreement with values obtained using Eq. (2). It shows that using PNR we can measure diffusivity precisely down to $1 \times$ $10^{-25} \mathrm{~m}^{2} \mathrm{~s}^{-1}$. Such small values of diffusivity are probably the lowest values ever measured [45,62].

Measured diffusivity at higher annealing temperature gives a snapshot picture for a fixed annealing time, an obtained variation of $D$ with temperature is shown in Fig. 7(a). As mentioned before, we also measured nitrogen diffusion using SIMS and for this purpose we prepared a special trilayer structure $\mathrm{Si}(\mathrm{Sub}) \mid.\left[\mathrm{Fe}-\mathrm{X}^{-}{ }^{\mathrm{nat}} \mathrm{N}(110 \mathrm{~nm})\left|\mathrm{Fe}-\mathrm{X}^{15} \mathrm{~N}(2 \mathrm{~nm})\right| \mathrm{Fe}-\right.$ $\mathrm{X}^{-\mathrm{nat}} \mathrm{N}(110 \mathrm{~nm})$ ], such structure is expected to give a peak when looking at ${ }^{15} \mathrm{~N}$ depth profile. As samples are annealed broadening of this peak provides information about nitrogen self-diffusion. Applying thin films solution to Fick's law, the tracer concentration of ${ }^{15} \mathrm{~N}$ with penetration depth (say $x$ ) can be expressed as [63]

$$
c(x, t)=\frac{\text { const. }}{2 \sqrt{\pi D t}} \exp \left(\frac{-x^{2}}{4 D t}\right) .
$$

Here $t$ is annealing time and $D$ is the diffusion coefficient. Figure 8 shows SIMS depth profile of $\mathrm{Fe}-\mathrm{N}, \mathrm{Fe}-\mathrm{Al}-\mathrm{N}$, and $\mathrm{Fe}-\mathrm{Zr}-\mathrm{N}$ samples annealed at various temperatures. Here again we find that as annealing temperature is increased, broadening of the ${ }^{15} \mathrm{~N}$ peak is more for the Fe-N and Fe-Zr-N samples as

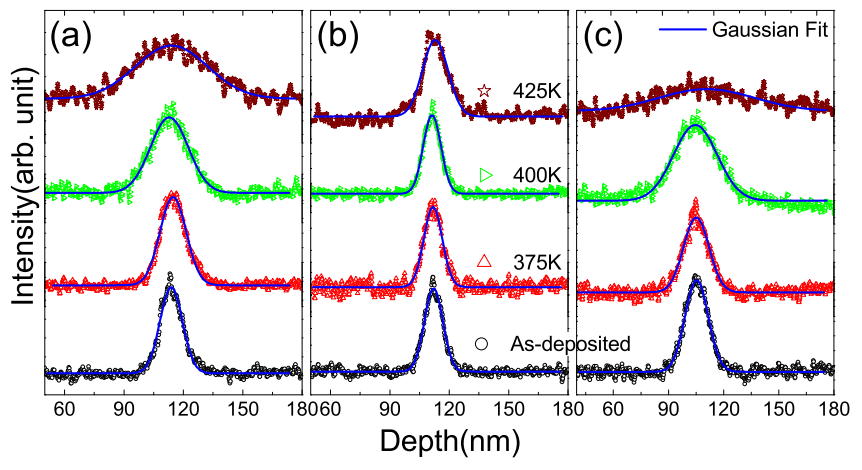

FIG. 8. (Color online) ${ }^{15} \mathrm{~N}$ SIMS depth profile of Sub.|[Fe-X$\left.\mathrm{N}(110 \mathrm{~nm})\left|\mathrm{Fe}-\mathrm{X}-{ }^{15} \mathrm{~N}(2 \mathrm{~nm})\right| \mathrm{Fe}-\mathrm{X}-\mathrm{N}(110 \mathrm{~nm})\right]$ trilayer samples with $\mathrm{X}=0$ (a), Al (b), and $\mathrm{Zr}$ (c) in the as-deposited state and after annealing at various temperatures. compared to the Fe-Al-N sample. Fitting SIMS profile with a Gaussian function according to Eq. (3) yields $D$ as

$$
D=\frac{\sigma_{t}^{2}-\sigma_{0}^{2}}{2 t} \text {. }
$$

Here $\sigma$ is the standard deviation of the Gaussian depth profile before annealing $(t=0)$ and after an annealing time of $t$. Obtained values of $D$ are plotted in Fig. 7(b). It may be noted that the depth resolution of SIMS is relatively poor (as compared to reflectivity). Therefore, absolute values of diffusivity may differ slightly, still the behavior of nitrogen diffusion is similar to that obtained with PNR measurements. Since in the $\mathrm{Zr}$ doped sample nitrogen diffusion was so fast that it was not possible to measure it with PNR, in SIMS measurements it can be clearly seen that with $\mathrm{Zr}$ doping nitrogen diffusion become even faster as compared to the undoped sample. This is an important result, for deciding effective dopant in Fe-X-N thin films. From the shape of the ${ }^{15} \mathrm{~N}$ depth profiling information about the nitrogen diffusion mechanism can be estimated. In case of grain boundary diffusion it would scale linearly with $x^{6 / 5}(x=$ depth) $[64,65]$ and would not follow a Gaussian distribution as observed for volume type diffusion. Since in our case a profile can be fitted with a Gaussian, we expect that the $\mathrm{N}$ diffusion mechanism to be of volume type, predominantly.

On the basis of the above results, it can be clearly seen that nitrogen self-diffusion gets reduced only with $\mathrm{Al}$ doping. We therefore also performed PNR measurements with an isothermal annealing experiment in $\mathrm{Fe}-\mathrm{N}$ and $\mathrm{Fe}-\mathrm{Al}-\mathrm{N}$ samples at 368, 398, and $413 \mathrm{~K}$ for different annealing time. Figures 9(a) and 9(b) shows PNR patterns of $\mathrm{Fe}-\mathrm{N}$ and $\mathrm{Fe}-\mathrm{Al}-\mathrm{N}$ samples annealed at $368 \mathrm{~K}$ for different times. Here

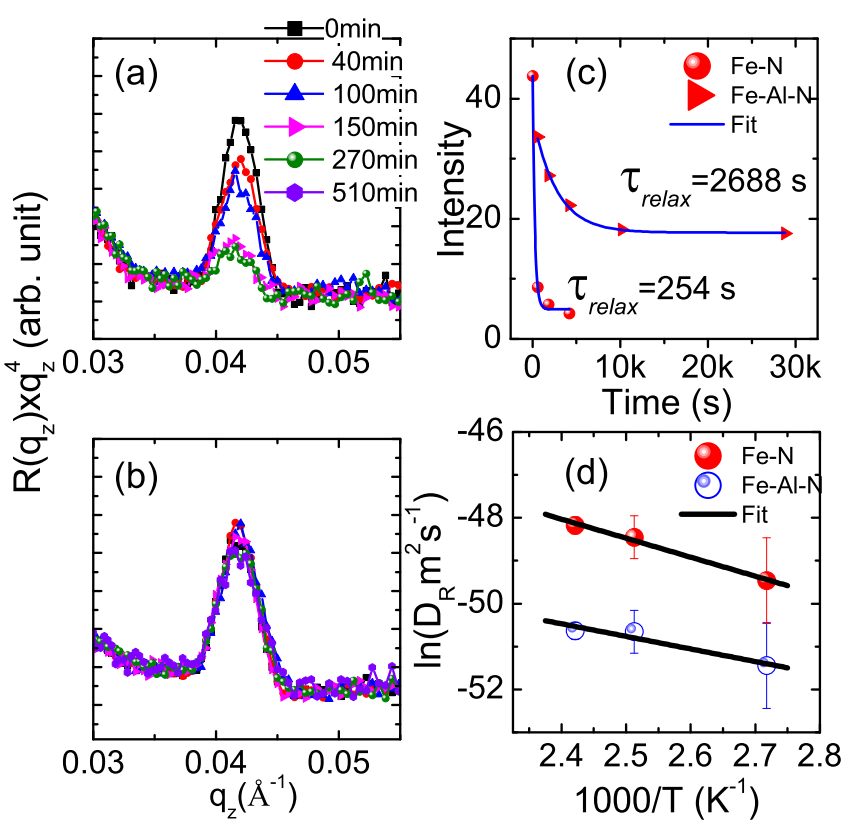

FIG. 9. (Color online) PNR patterns of (a) Sub.|[Fe-N(9.4 $\left.\mathrm{nm}) \mid \mathrm{Fe}-{ }^{15} \mathrm{~N}(9.4 \mathrm{~nm})\right]_{\times 25}$ and (b) Sub. $\mid[\mathrm{Fe}-\mathrm{Al}-\mathrm{N}(9.2 \mathrm{~nm}) \mid \mathrm{Fe}-\mathrm{Al}-$ $\left.{ }^{15} \mathrm{~N}(9.2 \mathrm{~nm})\right]_{\times 25}$ samples annealed at $368 \mathrm{~K}$ for different time period. (c) Variation of Bragg peak intensity with the annealing time for the above samples annealed at $415 \mathrm{~K}$. (d) Arrhenius behavior of nitrogen diffusion for the Fe-N and Fe-Al-N samples. 
intensity was multiplied by $q_{z}^{4}$ to remove decay due to Fresnel reflectivity. On comparing the reflectivity patterns, it can be clearly seen that in an undoped sample significant $\mathrm{N}$ diffusion started even at $368 \mathrm{~K}$ which increases further with increasing annealing time and attains a state of relaxation, whereas in the Al doped sample only marginal diffusion takes place. Figure 9(c) compares variation of intensity at Bragg peak with time for the Fe-N and Fe-Al-N samples annealed at $413 \mathrm{~K}$. It can be seen that intensity decays exponentially with annealing time. After fitting the data using $I(t)=I(0) \exp (-t / \tau)$, it was observed that relaxation time $\left(\tau_{\text {relax }}\right)$ for nitrogen diffusion increases by more than an order of magnitude with Al doping. Such increase in $\tau_{\text {relax }}$ provides further insight about involved diffusion mechanism, which is discussed in Sec. IV.

It is well known that, in the relaxed state, diffusivities follows Arrhenius-type behavior given by $D_{R}=$ $D_{0} \exp \left(-E / k_{B} T\right)$, with $D_{R}$ as diffusivity in relaxed state and $D_{0}$ as the pre-exponential factor, $E$ is activation energy, $T$ is annealing temperature, and $k_{B}$ is Boltzmann constant. Figure 9(d) shows Arrhenius type behavior of N self-diffusion in $\mathrm{Fe}-\mathrm{N}$ and $\mathrm{Fe}-\mathrm{Al}-\mathrm{N}$ thin films. A straight line fit to the data gives a value of $\ln \left(D_{0}\right)$ and $E$. For Fe-N and Fe-Al-N samples values of $\left[\ln \left(D_{0}\right)\right.$ and $\left.E\right]$ are $(-37.39 \pm 1,0.4 \mathrm{eV} \pm 0.05)$ and $(-43.42 \pm 1,0.25 \mathrm{eV} \pm 0.02)$, respectively. It can be seen that both $\ln \left(D_{0}\right)$ and $E$ decrease with Al doping.

Comparing the value of $\mathrm{N}$ diffusivity (e.g., for undoped sample) with those reported in literature (for bulk iron nitride), we find that our values are at least 3-4 orders of magnitude smaller [66]. As mentioned already, our samples are at saturation $\mathrm{N}$ concentration $(\sim 11$ at. $\%)$, therefore it is expected that a large fraction of interstitial sites are filled with $\mathrm{N}$ atoms. Therefore, the probability of obtaining neighboring vacant interstitial sites will be less leading to a suppression in nitrogen diffusivity [63].

In order to get a complete picture about diffusion in our samples, it was required that iron self-diffusion should also be measured. From our neutron reflectivity measurements, we find that there is no appreciable diffusion up to a temperature of $475 \mathrm{~K}$. In order to get a snapshot of diffusion, it was required that bilayer thickness $(13 \mathrm{~nm})$ should be decreased significantly. We therefore deposited substrate $\mid\left[{ }^{\text {nat }} \mathrm{Fe}-\mathrm{X}-\mathrm{N} / \mid{ }^{57} \mathrm{Fe}-\mathrm{X}\right.$ $\mathrm{N}]_{\times 10}(\mathrm{X}=0, \mathrm{Al})$ samples with bilayer thickness of about $4 \mathrm{~nm}$ under identical deposition conditions. In such samples Bragg peak in a neutron reflectivity pattern would occur at $q_{z}=0.16$ $\AA^{-1}$, which is too high to be measured with neutrons due to limited flux. It is known that for ${ }^{57} \mathrm{Fe}$, nuclear resonance reflectivity (NRR) is a very powerful technique to get precise information about the self-diffusion [61]. In addition, when measured in time domain, nuclear forward scattering (NFS) is Fourier transform of energy domain reflectivity that provides direct information about the local magnetic structure of Fe $[67,68]$.

NRR measurements were performed at P01 beamline of PETRA III both in time integral and time differential modes. For ${ }^{57} \mathrm{Fe}$ the lifetime of the excited state of nucleus is about $140 \mathrm{~ns}$, therefore a 40 bunch mode of PETRA III was used (pulse duration of about $176 \mathrm{~ns}$ ). In time integral mode, both electronic (prompt with few nanoseconds) and nuclear (delayed 40-140 ns) reflectivities can be measured simultaneously as they occur in different time windows and their scattering amplitude is given by $F=F_{\text {electronic }}+F_{\text {nuclear }}[61,68]$.

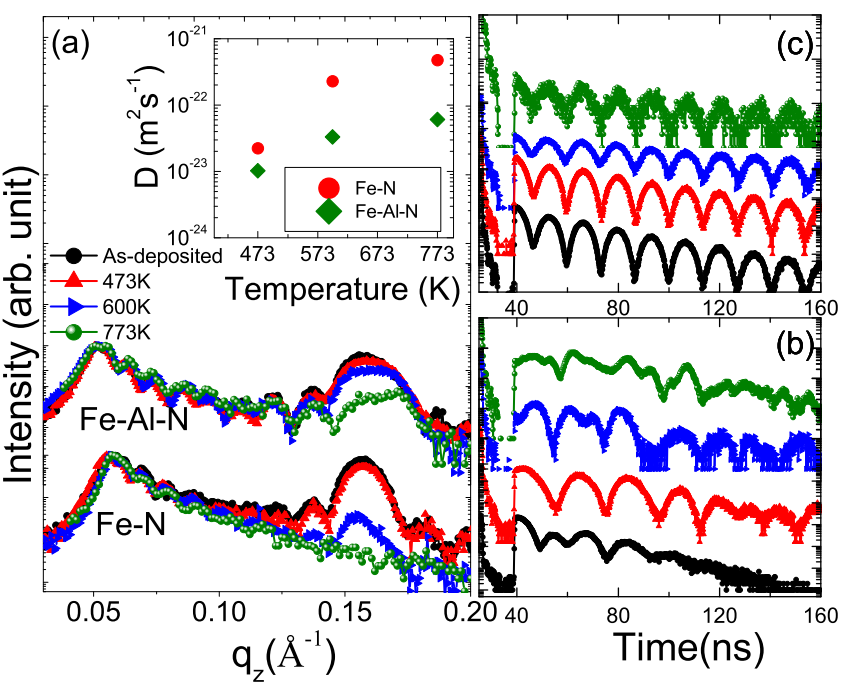

FIG. 10. (Color online) (a) NRR patterns of Sub.|[Fe-N(2.2 $\left.\mathrm{nm}) \mid{ }^{57} \mathrm{Fe}-\mathrm{N}(2.2 \mathrm{~nm})\right]_{\times 10}$ and Sub. $\mid\left[\mathrm{Fe}-\mathrm{Al}-\mathrm{N}(2 \mathrm{~nm}) \mid{ }^{57} \mathrm{Fe}-\mathrm{Al}-\mathrm{N}(2\right.$ $\mathrm{nm})]_{\times 10}$ samples in the as-deposited state and after annealing at various temperatures, inset of figure shows obtained values of self-diffusivity. Corresponding NFS patterns of (b) $\mathrm{Fe}-\mathrm{N}$ and (c) Fe-Al-N samples.

NRR measurements in time integral mode were carried out in $\theta-2 \theta$ mode and are shown in Fig. 10(a). On the other hand, NFS measurements were performed by sitting at the Bragg peak position and delayed photons were measured in time differential mode from 40 to $150 \mathrm{~ns}$ (within a bunch). The NFS spectra show a quantum beat pattern spread over delayed time, which arises due to interference between various hyperfine fields acting at the resonant nuclei [67].

Following a similar approach as mentioned for neutron reflectivity measurements, Fe self-diffusion was measured by annealing the samples at different temperatures and performing NRR measurements subsequently. Figure 10(a) shows NRR patterns of Fe-N and Fe-Al-N samples in the as-deposited state and after annealing samples at different temperatures. It can be seen that up to a temperature of $473 \mathrm{~K}, \mathrm{Fe}$ diffusion is negligible (also seen from PNR measurements Fig. 6) in both samples. In an undpoed sample Fe diffusion is appreciable at $600 \mathrm{~K}$ while at $773 \mathrm{~K}$ it diffuses completely. Whereas in an Al doped sample, only a marginal diffusion can be seen at 600 $\mathrm{K}$ while at $773 \mathrm{~K}$ Bragg peak can still be seen. The inset of Fig. 10(a) compares Fe diffusivity obtained from the decay in intensities of the Bragg peak using Eq. (2). As expected, Fe diffusivity suppress significantly with $\mathrm{Al}$ doping. In a recent study Fe self-diffusion was measured in ion beam sputtered $\mathrm{Fe}-\mathrm{N}$ samples prepared using $\mathrm{Al}$ and $\mathrm{Zr}$ doping and found $\mathrm{Fe}$ diffusion suppresses both with $\mathrm{Al}$ and $\mathrm{Zr}$ doping [69].

Corresponding NFS pattern obtained at the Bragg peak position are given in Figs. 10(b) and 10(c) for Fe-N and Fe-Al-N samples, respectively. It can be seen that for the Fe-N sample a somewhat complex NFS pattern arises due to interference between different hyperfine fields present in the sample. Whereas in case of the Fe-Al-N sample due to the predominant presence of single hyperfine field NFS spectra shows uniform quantum beats decaying with time. Moreover, NFS spectra for the $\mathrm{Fe}-\mathrm{N}$ sample shows variation 
with annealing indicating different phase formation, which are correlated with our XRD and CEMS results discussed in Secs. III A and III D. In case of the Al doped sample no appreciable change in the NFS pattern can be observed, it suggests that the local magnetic structure also gets stabilized with Al doping. These results are consistent with our XRD and CEMS measurements.

\section{DISCUSSION}

Combining results discussed above, a picture about the diffusion mechanism and the influence of dopants on diffusion can be drawn. We observed that $\mathrm{Fe}$ and $\mathrm{N}$ self-diffusion takes place in different temperature regimes. Up to a temperature of about $450 \mathrm{~K}, \mathrm{~N}$ diffusion dominates and $\mathrm{Fe}$ diffusion is negligible, only above $450 \mathrm{~K}$ considerable Fe diffusion can be observed. Importantly, both the structure and the magnetic properties remain almost unchanged even when nitrogen diffuses completely. It indicates that $\mathrm{N}$ diffusion has no significant role in the structural or magnetic changes in our samples. On the other hand, variation in the structural and magnetic properties seems to be driven by Fe self-diffusion which starts above $450 \mathrm{~K}$. However, dopants have clear intervention in affecting self-diffusion of both Fe and N. From our TEM measurements we observed that microstructure of the undoped sample is slightly different from doped samples. In spite of that $\mathrm{N}$ self-diffusion has similar behavior in undoped and $\mathrm{Zr}$ doped samples, but is completely different for Al doped samples. Clearly the difference in microstructure does not correlate with $\mathrm{N}$ self-diffusion behavior. Our SIMS measurements also ruled out the possibility of grain boundary diffusion of $\mathrm{N}$ which is expected to be highly dependent on the microstructure.

First, we will discuss the role of dopants on influencing $\mathrm{N}$ self-diffusion. It is known that up to a concentration of $\sim 11$ at. $\%, \mathrm{~N}$ atoms occupies interstitial sites within the Fe lattice. Numerous studies on self-diffusion behavior of light elements such as $\mathrm{H}, \mathrm{C}, \mathrm{O}, \mathrm{N}$, etc. reveal that they follow interstitial-type diffusion mechanism [70-73]. In the course of interstitial diffusion, $\mathrm{N}$ atoms try to find the most equilibrium interstitial sites by crossing a saddle point barrier. Moreover, interstitial diffusion is strongly affected by pressure, which alters available interstitial volume for diffusing $\mathrm{N}$ atoms [74]. In case of the undoped sample, due to the absence of any impeding force, $\mathrm{N}$ diffusion leads to its redistribution within the lattice. This redistribution favors nitrogen ordering, as observed from the sharpening in the peak corresponding to the $\alpha^{\prime \prime}$ phase in our XRD results (Fig 1). As mentioned in Sec. III A, with $\mathrm{Al}$ doping the average unit cell volume of $\mathrm{Fe}$ gets reduced by $\sim 0.5 \%$. This will also decrease the available interstitial volume for the diffusing $\mathrm{N}$ atoms. Therefore, the probability for finding equilibrium interstitial sites will be less resulting in slower $\mathrm{N}$ diffusion or a larger relaxation time, as observed with $\mathrm{Al}$ doping. On the contrary, with $\mathrm{Zr}$ doping the average unit cell volume of Fe gets expanded by $\sim 2 \%$. In this situation, availability of additional equilibrium interstitial sites may accelerate the diffusion process of $\mathrm{N}$ atoms. Similarly, enhanced $\mathrm{N}$ diffusion with Ti doping can be understood.

As pointed out earlier, thermal stability of Fe-X-N thin films are significantly affected by self-diffusion of Fe. Our results show that doping of Al has notably reduced the self-diffusion of Fe. Although we find that the structure and the magnetic stability gets improved with both $\mathrm{Al}$ as well as $\mathrm{Zr}$ doping. It indicates that the atomic size of dopants does not matter in suppressing $\mathrm{Fe}$ self-diffusion. It seems that the role of dopants on influencing the self-diffusion of $\mathrm{Fe}$ is completely different from $\mathrm{N}$ diffusion. Since $\Delta H_{f}^{\circ}$ for nitride formation of dopants is low, there is a large probability that $\mathrm{X}-\mathrm{N}$ layer may be formed in the grain boundary region, as observed in some reports $[25,75]$. This $\mathrm{X}-\mathrm{N}$ layer may act as a diffusion barrier for $\mathrm{Fe}$ [76]. Moreover, this barrier layer seems to have multiple effects as it not only suppresses Fe self-diffusion, it also hinders grain growth, leading to improved soft magnetic properties as observed in our samples with $\mathrm{Al}$ or $\mathrm{Zr}$ doping. The improvement in soft-magnetic properties of $\mathrm{Fe}-\mathrm{N}$ thin films with dopants was also found in previous reports [34,77,78]. Somewhat superior thermal stability with Al doping can also be understood from the fact that only with $\mathrm{Al}$ doping $\mathrm{N}$ diffusion suppresses.

\section{CONCLUSION}

In the present work we have studied the role of $\mathrm{Fe}$ and $\mathrm{N}$ self-diffusion on influencing the structure, magnetic properties, and thermal stability of $\mathrm{Fe}-\mathrm{X}-\mathrm{N}$ thin films. It was observed that with $\mathrm{Al}$ or $\mathrm{Zr}$ doping thermal stability gets significantly improved. Additionally, magnetization measurements revealed that soft-magnetic properties also gets improved with dopants. To understand the observed effects, detailed $\mathrm{Fe}$ and $\mathrm{N}$ self-diffusion measurements were performed. It was found that dopants have clear intervention in affecting $\mathrm{Fe}$ and $\mathrm{N}$ self-diffusion, however, the mechanism leading to the suppression of Fe and $\mathrm{N}$ self-diffusion is different. In case of $\mathrm{N}$ self-diffusion, atomic size of dopants plays a crucial role. It was observed that $\mathrm{N}$ diffusion gets significantly reduced when the atomic size of dopants is smaller than that of Fe. A dopant with smaller size lead to compression in the Fe lattice, whereas lattice expansion takes place when a larger (than Fe) dopant is used. Such lattice distortion caused by dopants results in alteration of available interstitial volume for diffusing $\mathrm{N}$ atoms. On the other hand, Fe self-diffusion gets suppressed with any dopant, if its heat of formation is significantly smaller than that of Fe-N. This happens due to the formation of a diffusion barrier layer which not only suppresses self-diffusion of Fe but also hinders the grain growth leading to improved soft-magnetic properties. In addition, it can be concluded that $\mathrm{N}$ diffusion has a less significant role (as compared to $\mathrm{Fe}$ ) in affecting the thermal instability in Fe-N thin films.

\section{ACKNOWLEDGMENTS}

A part of this work was performed at AMOR, Swiss Spallation Neutron Source, Paul Scherrer Institute, Villigen, Switzerland and at P01 beamline, PETRA III, DESY, Germany. We acknowledge Department of Science and Technology, New Delhi for providing financial support to carry out PNR and NRR experiments. We acknowledge V. R. Reddy for CEMS, R. J. Chaudhary for S-VSM, and Layanta Behera for help provided in XRD and SIMS measurements. One of the authors (A.T.) gives thanks to CSIR India for a research fellowship. 
[1] J. M. D. Coey and P. A. I. Smith, J. Magn. Magn. Mater. 200, 405 (1999).

[2] C. Navío, J. Alvarez, M. J. Capitan, F. Yndurain, and R. Miranda, Phys. Rev. B 78, 155417 (2008).

[3] S. Kokado, N. Fujima, K. Harigaya, H. Shimizu, and A. Sakuma, Phys. Rev. B 73, 172410 (2006).

[4] T. Liapina, A. Leineweber, and E. Mittemeijer, Scr. Mater. 48, 1643 (2003).

[5] X. Z. Ding, F. M. Zhang, J. S. Yan, H. L. Shen, X. Wang, X. H. Liu, and D.-F. Shen, J. Appl. Phys. 82, 5154 (1997).

[6] M. H. Kryder, IEEE Trans. Magn. 25, 4358 (1989).

[7] H. Jiang, K. Tao, and H. Li, J. Phys.: Condens. Matter 6, L279 (1994).

[8] H. Sawada, A. Nogami, T. Matsumiya, and T. Oguchi, Phys. Rev. B 50, 10004 (1994).

[9] J. Das, S. S. Kalarickal, K.-S. Kim, and C. E. Patton, Phys. Rev. B 75, 094435 (2007).

[10] R. Gupta and M. Gupta, Phys. Rev. B 72, 024202 (2005).

[11] F. Tessier, A. Navrotsky, R. Niewa, A. Leineweber, H. Jacobs, S. Kikkawa, M. Takahashi, F. Kanamaru, and F. J. DiSalvo, Solid State Sci. 2, 457 (2000).

[12] T. K. Kim and M. Takahashi, Appl. Phys. Lett. 20, 492 (1972).

[13] M. Takahashi and H. Shoji, J. Magn. Magn. Mater. 208, 145 (2000).

[14] N. Ji, M. S. Osofsky, V. Lauter, L. F. Allard, X. Li, K. L. Jensen, H. Ambaye, E. Lara-Curzio, and J.-P. Wang, Phys. Rev. B 84, 245310 (2011).

[15] J. M. Gallego, S. Y. Grachev, D. M. Borsa, D. O. Boerma, D. Écija, and R. Miranda, Phys. Rev. B 70, 115417 (2004).

[16] M. Georgieva, N. Telling, P. Grundy, C. Faunce, and G. Jones, J. Appl. Phys. 96, 2923 (2004).

[17] R. Gupta, A. Gupta, W. Leitenberger, and R. Rüffer, Phys. Rev. B 85, 075401 (2012).

[18] A. Gupta, R. Dubey, W. Leitenberger, and U. Pietsch, Appl. Phys. Lett. 92, 052504 (2008).

[19] K. Nakajima, S. Okamoto, and T. Okada, J. Appl. Phys. 65, 4357 (1989).

[20] Y. Jiang, M. Al Mehedi, E. Fu, Y. Wang, and J.-P. Wang, J. Appl. Phys. 115, 17A753 (2014).

[21] N. G. Chechenin, A. van Veen, H. Schut, A. R. Chezan, D. O. Boerma, T. Vystavel, and J. T. M. D. Hosson, J. Phys.: Condens. Matter 15, 7663 (2003).

[22] H. Y. Wang, E. Y. Jiang, Z. W. Ma, Y. J. He, and H. S. Huang, J. Phys.: Condens. Matter 11, 989 (1999).

[23] Y. Takeshima, N. Ishiwata, T. Korenari, and H. Urai, J. Appl. Phys. 73, 6576 (1993).

[24] B. Viala, M. K. Minor, and J. A. Barnard, J. Appl. Phys. 80, 3941 (1996).

[25] H. Y. Wang, E. Y. Jiang, H. L. Bai, P. Wu, Y. Wang, and F. F. Gong, J. Phys.: Condens. Matter 9, 8443 (1997).

[26] L. Varga, H. Jiang, T. J. Klemmer, W. D. Doyle, and E. A. Payzant, J. Appl. Phys. 83, 5955 (1998).

[27] Y. Chen, C. Qian, C.-Y. Hung, and M. Miller, J. Appl. Phys. 87, 5864 (2000).

[28] Y.-K. Liu and M. H. Kryder, Appl. Phys. Lett. 77, 426 (2000).

[29] A. Chezan, C. Craus, N. Chechenin, L. Niesen, and D. Boerma, Phys. Status Solidi A 189, 833 (2002).
[30] J. Rantschler, Y. Ding, S.-C. Byeon, and C. Alexander, J. Appl. Phys. 93, 6671 (2003).

[31] Y.-K. Liu, M. H. Kryder, D. H. Ryan, and Z. Altounian, J. Appl. Phys. 93, 6471 (2003).

[32] S. S. Kalarickal, P. Krivosik, J. Das, K. S. Kim, and C. E. Patton, Phys. Rev. B 77, 054427 (2008).

[33] F. Xu, S. Li, and C. K. Ong, J. Appl. Phys. 109, $07 \mathrm{D} 322$ (2011).

[34] R. Gupta, A. Tayal, S. M. Amir, M. Gupta, A. Gupta, M. Horisberger, and J. Stahn, J. Appl. Phys. 111, 103520 (2012).

[35] M. Kopcewicz, J. Jagielski, G. Gawlik, and A. Grabias, J. Appl. Phys. 78, 1312 (1995).

[36] D. B. Evans, Ph.D. Thesis, University of Michigan, 1963.

[37] E. Clementi, D. L. Raimondi, and W. P. Reinhardt, J. Chem. Phys. 47, 1300 (1967).

[38] L. Hultman, Vacuum 57, 1 (2000).

[39] C. Navío, M. J. Capitán, J. Álvarez, R. Miranda, and F. Yndurain, New J. Phys. 12, 073004 (2010).

[40] M. Gupta, A. Gupta, J. Stahn, M. Horisberger, T. Gutberlet, and P. Allenspach, Phys. Rev. B 70, 184206 (2004).

[41] M. Gupta, A. Gupta, S. Chakravarty, R. Gupta, and T. Gutberlet, Phys. Rev. B 74, 104203 (2006).

[42] M. Gupta, A. Gupta, J. Stahn, and T. Gutberlet, New J. Phys. 10, 053031 (2008).

[43] E. Huger, J. Rahn, J. Stahn, T. Geue, and H. Schmidt, Phys. Rev. B 85, 214102 (2012).

[44] S. M. Baker, G. S. Smith, N. J. S. Brown, M. Nastasi, and K. Hubbard, Phys. Rev. B 55, 7255 (1997).

[45] H. Schmidt, M. Gupta, and M. Bruns, Phys. Rev. Lett. 96, 055901 (2006).

[46] E. Huger, H. Schmidt, T. Geue, J. Stahn, U. Tietze, D. Lott, A. Markwitz, U. Geckle, and M. Bruns, J. Appl. Phys. 109, 093522 (2011).

[47] M. Gupta, A. Tayal, A. Gupta, R. Gupta, J. Stahn, M. Horisberger, and A. Wildes, J. Appl. Phys. 110, 123518 (2011).

[48] S. Chakravarty, M. Gupta, A. Gupta, S. Rajagopalan, A. Balamurugan, A. Tyagi, U. Deshpande, M. Horisberger, and T. Gutberlet, Acta Mater. 57, 1263 (2009).

[49] D. M. Borsa and D. O. Boerma, Hyp. Int. 151-152, 31 (2003).

[50] B. D. Cullity, Elements of X-ray Diffraction (Addison-Wesley, Reading, MA, 1978).

[51] S. J. Blundell and J. A. C. Bland, Phys. Rev. B 46, 3391 (1992).

[52] F. Ott, SIMULREFLEC (V1.7 2011) http://wwwllb.cea.fr/prism/programs/simulreflec/simulreflec.html.

[53] J.-F. Bobo, H. Chatbi, M. Vergnat, L. Hennet, O. Lenoble, Ph. Bauer, and M. Piecuch, J. Appl. Phys. 77, 5309 (1995).

[54] H. Naganuma, R. Nakatani, Y. Endo, Y. Kawamura, and M. Yamamoto, Jpn. J. Appl. Phys. 43, 4166 (2004).

[55] D. Buntinx, S. Brems, A. Volodin, K. Temst, and C. Van Haesendonck, Phys. Rev. Lett. 94, 017204 (2005).

[56] V. R. Reddy, O. Crisan, A. Gupta, A. Banerjee, and V. Kuncser, Thin Solid Films 520, 2184 (2012).

[57] R. Brand, Wissenschaftlich Elektronik GmbH, Starnberg (1995).

[58] U. Gonser and H.-D. Pfannes, J. Phys. Colloq. 35, C6-113 (1974). 
[59] M. P. Rosenblum, F. Spaepen, and D. Turnbull, Appl. Phys. Lett. 37, 184 (1980).

[60] J. Speakman, P. Rose, J. Hunt, N. Cowlam, R. E. Somekh, and A. Greer, J. Magn. Magn. Mater. 156, 411 (1996).

[61] A. Gupta, M. Gupta, S. Chakravarty, R. Rüffer, H.-C. Wille, and O. Leupold, Phys. Rev. B 72, 014207 (2005).

[62] H. Schmidt, M. Gupta, T. Gutberlet, J. Stahn, and M. Bruns, Acta Mater. 56, 464 (2008).

[63] H. Mehrer, Diffusion in Solids: Fundamentals, Methods, Materials, Diffusion-Controlled Processes (Springer, Berlin, 2007), Vol. 155.

[64] J. C. Fisher, J. Appl. Phys. 22, 74 (1951).

[65] Y. Mishin and C. Herzig, Mater. Sci. Eng. A 260, 55 (1999).

[66] J. da Silva and R. B. McLellan, Mater. Sci. Eng. 26, 83 (1976).

[67] E. Gerdau, R. Rüffer, R. Hollatz, and J. P. Hannon, Phys. Rev. Lett. 57, 1141 (1986).
[68] R. Röhlsberger, J. Bansmann, V. Senz, K. L. Jonas, A. Bettac, K. H. Meiwes-Broer, and O. Leupold, Phys. Rev. B 67, 245412 (2003).

[69] A. Tayal, M. Gupta, D. Kumar, V. Reddy, A. Gupta, S. Amir, P. Korelis, and J. Stahn, J. Appl. Phys. (to be published).

[70] J. Snoek, Physica 8, 711 (1941).

[71] C. P. Flynn and A. M. Stoneham, Phys. Rev. B 1, 3966 (1970).

[72] C. Zener, J. Appl. Phys. 22, 372 (1951).

[73] C. A. Wert, J. Appl. Phys. 21, 1196 (1950).

[74] A. Bosman, P. Brommer, and G. Rathenau, Physica 23, 1001 (1957).

[75] Y. Ding, S. C. Byeon, and C. Alexander, IEEE Trans. Magn. 37, 1776 (2001).

[76] M.-A. Nicolet, Thin Solid Films 52, 415 (1978).

[77] A. Tayal, M. Gupta, A. Gupta, M. Horisberger, and J. Stahn, Thin Solid Films 536, 39 (2013).

[78] N. Ishiwata, C. Wakabayashi, and H. Urai, J. Appl. Phys. 69, 5616 (1991). 